\title{
REGULACIÓN DE LOS BOSQUES EN EL DERECHO ESPAÑOL Y DE LA UNIÓN EUROPEA
}

\author{
José Antonio Moreno Molina ${ }^{1}$ \\ Universidad Castilla La Mancha (UCLM)
}

\section{RESUMEN}

Se analiza en el trabajo la disciplina normativa forestal en el ordenamiento jurídico español, que se encuentra marcada por las previsiones constitucionales de protección del medio ambiente y por la Ley de Montes de 2003, cuya regulación de los bosques se enfoca en sus valores de carácter ambiental. Utiliza la norma un concepto amplio de bosque como terreno que principalmente cumple funciones ambientales y protectoras; e incorpora las diversas funciones del territorio forestal y da entrada a las Comunidades autónomas en el margen de regulación sobre terrenos agrícolas abandonados, suelos urbanos y urbanizables y la determinación de la dimensión de la unidad mínima que será considerada monte a efectos de la ley. También se estudian las principales actuaciones de la Unión Europea en materia forestal, destacando cómo carece de una política forestal integral.

Palabras clave: bosques, ecosistema forestal, competencias forestales, Unión Europea, medio ambiente

\section{REGULATION OF FORESTS IN SPANISH LAW AND THE EUROPEAN UNION}

\section{ABSTRACT}

In this paper, the normative forestry discipline in the Spanish legal system is analyzed, which is marked by the constitutional provisions of environmental protection and by the Forestry Law of 2003, whose regulation of forests focuses on their environmental value. The norm adopts a broad concept of the forest as a land that primarily fulfills environmental and protective

1 Doctor en Derecho con la máxima calificación por la UCLM. Licenciado en Derecho por la UCLM. Catedrático de Derecho Administrativo de la UCLM. Director del Máster en "Derecho de la Contratación Pública" de la UCLM. ORCID: https://orcid.org/0000-0001-5504-6880 / e-mail: JoseAntonio.Moreno@uclm.es 
functions; it also incorporates the various functions of the forest territory and includes Autonomous Communities in the fringes of regulation on abandoned agricultural land, urban and developable land, and the determination of the size of the minimum unit that will be considered a forest for the purposes of the law. The main actions of the European Union regarding forestry are also analyzed, highlighting how it lacks a comprehensive forest policy.

Keywords: environment; European Union; forest ecosystem; forestry skills; forests. 


\section{INTRODUCCIÓN}

La disciplina normativa forestal se ha encontrado marcada a la largo de la historia en el Derecho español por las diversas funciones que el bosque cumple, ya sea como bien económico o productivo, como instrumento de defensa hidrogeológica del territorio, como valor ambiental en sentido amplio (protección de la fauna, flora, atmósfera, aguas, clima, ecosistema), como susceptible de un aprovechamiento recreativo o turístico o por sus funciones sociales. En efecto, las distintas normas que desde el siglo pasado se han aprobado en la materia, han impuesto unas obligaciones sobre los bosques para tutelar los distintos intereses públicos que más han preocupado en cada momento o período histórico².

Sólo a partir de la Constitución española de 1978 la protección de los bosques ha estado marcada por sus funciones ecológicas o reguladoras de la dinámica de la biosfera, de forma que las normas han tenido en cuenta que son un recurso natural cuya contribución es decisiva en el mantenimiento del ciclo de la vida y en la conservación del medio ambiente.

En España una de las funciones ambientales más importantes de los bosques es la protección del suelo contra la erosión, principalmente en su modalidad hídrica. Esta erosión no solo ocasiona importantes pérdidas de fertilidad del suelo sino que también es causa de otros efectos indeseados que merman la efectividad de ciertas infraestructuras, en especial las de comunicación vial y las hidráulicas. La existencia de masas forestales es esencial, sobre todo en terrenos en declive, para paliar los efectos negativos del fenómeno erosivo, así como para la contención de riadas y la regulación de la de escorrentía.

Pero también hay que destacar el papel de los bosques como asilo y refugio de la fauna y la flora, la mejora de la calidad de las aguas, la regulación del régimen hidrológico y la influencia sobre el clima y la atmósfera. En un momento como el actual en que está en vigor el Protocolo de Kyoto sobre reducción de gases con efecto invernadero de la Convención Marco de las Naciones Unidas sobre el Cambio Climático (aprobado en la Unión Europea por la Decisión del Consejo de 25 de abril de 2002), resulta fundamental el papel de los bosques como sumideros de dióxido de carbono, depósitos de los gases de efecto invernadero y también por la producción de biomasa y su potencial en materia de energías renovables ${ }^{3}$.

2 Es más, las primeras normas forestales se pueden encontrar en nuestro ordenamiento en la baja Edad Media. Sin embargo, hasta el siglo XIX no se puede hablar de un verdadero sistema forestal. Sobre la evolución histórica de la protección jurídica de los montes en España puede verse Guaita $(1956 ; 1986)$ y Parada Vazquez (1989).

3 Resulta imprescindible al respecto el estudio de Sarasíbar Iriarte (2007). 


\section{PREVISIONES EN LA CONSTITUCIÓN ESPAÑOLA}

La Constitución española de 1978 marcó el decisivo punto de inflexión en la regulación jurídica de los bosques e introdujo un importante cambio de enfoque desde el que contemplar toda la normativa forestal (LAZARO BENITO, 1993). En efecto, si por un lado se van a reconocer competencias de desarrollo legislativo y ejecutivo a las regiones o Comunidades autónomas en la materia, por otro se elevan al rango de principios rectores de la política económica y social tanto el derecho a disfrutar de un medio ambiente adecuado para el desarrollo de la persona, como el deber de conservarlo.

Faltaba en la legislación preconstitucional de montes una consideración del bosque en su conjunto como objeto de protección. La Ley de Montes de 1957 protegía sólo determinados bosques que por su ubicación o características cumplen una función relevante, sobre todo, en relación con los procesos hidrológicos (ESTEVE PARDO, 1995). Entre los montes propiedad de particulares ( $2 / 3$ del total), prácticamente sólo eran considerados protectores $\mathrm{y}$, por tanto, se sujetaban a una regulación pública los bosques situados en las cabeceras de cuencas hidrográficas ${ }^{4}$.

Pero, junto a esta consagración constitucional del derecho al medio ambiente, el apartado segundo del art. 45 del texto constitucional contiene un decisivo mandato para los poderes públicos, al establecer que éstos "velarán por la utilización racional de todos los recursos naturales, con el fin de proteger y mejorar la calidad de la vida y defender y restaurar el medio ambiente, apoyándose en la indispensable solidaridad colectiva".

Partiendo del concepto genérico de utilización racional de los recursos naturales que establece el art. 45 de la Constitución, dentro del cual cabe incluir destacadamente a los montes y espacios forestales por su importante contribución al sostenimiento de un medio ambiente adecuado, la principal norma estatal de desarrollo de este precepto constitucional, la Ley 4/1989, de Conservación de los Espacios Naturales y de la Flora y Fauna Silvestre (que fue más tarde derogada por la Ley 42/2007, de 13 de diciembre, del Patrimonio Natural y de la Biodiversidad), va a marcar un importante punto de inflexión en el ámbito forestal. La norma, en cumplimiento del art.

4 En España, una regulación hidrológico-forestal se puede encontrar desde finales del siglo XIX: en la Ley de Aguas de 1879 (art. 59); en el Real Decreto de 3 de febrero de 1988, que establece el Plan sistemático de repoblación de cabecera de cuencas hidrográficas; en el Real Decreto de 7 de junio de 1901, por el que se creó el Servicio Hidrológico Forestal de la Nación; en la la Ley de 18 de octubre de 1941, de repoblación forestal de las riberas y los ríos; y, sobre todo, en la Ley de Montes de 1957 (art. 25) y en su reglamento de 1962 (art. 341.1), y en la Ley de Aguas de 1985. Sobre esta histórica relación entre bosques y agua en nuestro país, véase De Vicente Domingo (1995, p. 67 y ss). 
45.2, y conforme a lo dispuesto en el art. 149.1.23 de la Constitución, tuvo como objetivo el establecimiento de normas de protección, conservación, restauración y mejora de los recursos naturales y, en particular, las relativas a los espacios naturales y a la flora y fauna silvestres.

Sobre la base de los principios inspiradores de la Ley (mantenimiento de los procesos ecológicos esenciales y de los sistemas vitales básicos; utilización ordenada de los recursos y preservación de la diversidad genética, la variedad, singularidad y belleza de los ecosistemas naturales y del paisaje), es el artículo 9 de la Ley 4/89 el que constituye desde su aprobación pauta obligada de referencia en materia forestal. En efecto, este precepto dispuso en su apartado primero que "la utilización del suelo con fines agrícolas, forestales y ganaderos deberá orientarse al mantenimiento del potencial biológico y capacidad productiva del mismo, con respeto a los ecosistemas del entorno".

Pero el precepto fue más allá al fijar expresamente la pauta por la que debía discurrir la actuación de la Administraciones públicas en materia forestal. En efecto, en el apartado segundo el art. 9 estableció que esta acción de las Administraciones Públicas "se orientará a lograr la protección, restauración, mejora y ordenado aprovechamiento de los montes, cualquiera que sea su titularidad, y su gestión técnica deberá ser acorde con sus características legales, ecológicas, forestales y socio-económicas, prevaleciendo en todo caso el interés público sobre el privado".

De esta forma, la Ley 4/89 consagró la nueva dirección de la política y la acción forestal a desarrollar por nuestras Administraciones públicas, en la que el componente ambiental pasó a ser prioritario.

La disposición citada propuso como finalidad básica a perseguir el ordenado aprovechamiento de los montes, con independencia de su propiedad. Entre otros aspectos relevantes de la Ley 4/89, también hay que destacar muy significativamente el planeamiento de los recursos naturales. En efecto, la Ley creó, como instrumento novedoso en nuestro ordenamiento jurídico, los Planes de Ordenación de los Recursos Naturales y las Directrices para la Ordenación de los Recursos Naturales (arts. 4 y ss.).

\section{EL REPARTO DE COMPETENCIAS EN MATERIA FORESTAD ENTRE EL ESTADO Y LAS COMUNIDADES AUTÓNOMAS}

De acuerdo con el artículo 149.1.23 de la Constitución española, el Estado central tiene reservada la competencia sobre la legislación básica en materia de montes, aprovechamientos forestales y vías pecuarias, 
correspondiendo a las Comunidades autónomas, en general, el resto de las funciones normativas y ejecutivas en la materia.

Pero sobre los bosques, que son un recurso natural de importancia fundamental para la conservación del medio ambiente, inciden también de manera decisiva, como ha destacado el Tribunal Constitucional (Sentencias 64/1982, de 4 de noviembre - RTC 1982, 64 -, 102/1985, de 26 de junio TC (Sala Pleno) - RTC 1995, 102 - y 32/2006, de 1 febrero - RTC 2006/32), las regulaciones normativas basadas en la competencia en materia medioambiental, previstas en los artículos 148.1.9 y 149.1.23 CE, que permiten a las Comunidades autónomas asumir competencias de gestión en materia de protección del medio ambiente, otorgando al Estado la competencia exclusiva para dictar la legislación básica, sin perjuicio de las facultades autonómicas para dictar normas adicionales de protección.

Además de esos títulos competenciales, tanto las Comunidades autónomas como el Estado poseen otras competencias que inciden sobre la materia forestal (pueden verse al respecto las exposiciones de motivos de la Ley estatal 43/2003 y de la Ley de Castilla-la Mancha 3/2008), como son las que ostentan en relación con la ordenación del territorio y la política territorial, el urbanismo, la vivienda, la agricultura, los bienes de dominio público y patrimoniales cuya titularidad les corresponde, agricultura y ganadería, fomento y coordinación de la investigación, promoción del deporte y de la adecuada utilización del ocio, estadística y sobre pastos, espacios naturales protegidos, zonas de montaña, el régimen jurídico de las Administraciones públicas, legislación civil y la coordinación y planificación de la actividad económica (LAZARO BENITO, 1993).

En la sentencia 71/1983, de 29 de julio (RTC 1983/71), el Tribunal Constitucional señaló que es el hecho de incidir sobre espacios jurídicamente definidos como montes lo que determina su caracterización como materia de montes y, consecuentemente, el que se encuentre regulado por la legislación forestal.

La Ley estatal 43/2003, de 21 de noviembre, de Montes, modificada en este punto por la Ley 10/2006, de 28 de abril, clarifica en su artículo 7 las funciones en la materia de la Administración General del Estado, fundamentadas en su competencia de legislación básica en materia de montes, aprovechamientos forestales y medio ambiente. Recoge de esta forma el precepto la competencia estatal para la representación internacional de España en materia forestal; la definición de los objetivos generales de la política forestal española (aprobando documentos como la Estrategia 
forestal española, el Plan forestal español, el Programa de acción nacional contra la desertificación y el Plan nacional de actuaciones prioritarias de restauración hidrológico-forestal); la recopilación, elaboración y sistematización de la información forestal para mantener y actualizar la Estadística forestal española; el establecimiento de las directrices comunes para la normalización de los medios materiales y de los equipamientos de personal de extinción de incendios forestales en todo el territorio español, así como el despliegue de medios estatales de apoyo a las Comunidades autónomas, para la cobertura de los montes contra incendios; el ejercicio de las funciones necesarias para la adopción de medidas fitosanitarias urgentes, así como velar por la adecuada ejecución, coordinación y seguimiento de las mismas, en situaciones excepcionales en las que exista grave peligro de extensión de plagas forestales, de conformidad con el artículo 16 de la Ley 43/2002, de 20 de noviembre, de sanidad vegetal; la promoción de planes de formación y empleo del sector forestal; la elaboración de programas de mejora genética y conservación de recursos genéticos forestales de ámbito nacional, así como el establecimiento de normas básicas sobre procedencia, producción, utilización y comercialización de los materiales forestales de reproducción y, en particular, la determinación de sus regiones de procedencia y el mantenimiento del Registro y del Catálogo Nacional de Materiales de Base; la elaboración y aprobación de las Instrucciones básicas para la ordenación y aprovechamiento de montes; el fomento de la investigación científica y la innovación tecnológica en el ámbito forestal; la coordinación de la llevanza del Catálogo de Montes de Utilidad Pública, así como la del Registro de montes protectores y montes con otras figuras de especial protección y la colaboración en el diseño de las redes, la recopilación y comunicación a los órganos comunitarios de los datos obtenidos por las Comunidades autónomas en su ámbito territorial, procedentes de las parcelas de las redes europeas para el seguimiento de las interacciones del monte con el medio ambiente.

En todo caso, la Ley 43/2003 opta con claridad por la colaboración y cooperación entre las Administraciones para beneficio de un medio forestal que no entiende de fronteras administrativas.

En efecto, el complejo esquema español de distribución de competencias en materia de montes, aprovechamientos forestales y protección del medio ambiente, sobre el que se pronuncia la STC 21/1999, de 25 de febrero de 1999 (RTC 1999/21), conduce como camino indispensable hacia una estrecha colaboración y cooperación interadministrativa. Como 
ha señalado abundante jurisprudencia del Tribunal Constitucional (SSTC 80/1985 - RTC 1985/80 -, 18/1982 - RTC 1982/18 - y 96/1986 - RTC 1986/96 -, entre otras), existe un deber general de colaboración entre el Estado y las Comunidades autónomas que no es preciso justificar mediante preceptos concretos, porque es de esencia al modelo de organización territorial del Estado implantado por la Constitución. La materia forestal es un campo propicio para la celebración de Acuerdos o Convenios entre nuestras distintas Administraciones públicas (Estado, Comunidades autónomas y Entidades Locales), como forma de vertebrar el necesario principio de cooperación que se halla presente en la sustancia del Estado Autonómico, como reiteradamente ha proclamado el máximo intérprete constitucional (STC 146/1992 -RTC 1992/146).

En este sentido, en uso de sus competencias en la materia, existe ya una importante legislación autonómica forestal, entre la que se pueden destacar las siguientes normas: Ley 6/1988, de 13 de marzo, Forestal de Cataluña; Ley 13/1990, de 31 de diciembre, de Protección y Desarrollo del Patrimonio Forestal de Navarra; Ley 2/1992, de 15 de junio, de Ordenación Forestal de Andalucía; Ley 3/1993, de 9 de diciembre, Forestal de Valencia; Ley 5/1994, de 16 de mayo, de Fomento de los Montes Arbolados de Castilla-León; Ley de 10 de febrero de 1995 de Protección y Desarrollo del Patrimonio Forestal de Madrid y Ley 16/1995, de 4 de mayo, Forestal y de Protección de la naturaleza de Madrid; Ley 15/2006, de 28 de diciembre, de Montes de Aragón; Ley 3/2004, de 23 de noviembre, de Montes y Ordenación Forestal del Principado de Asturias; Ley 3/2008, de 12 de junio, de Montes y Gestión Sostenible de Castilla-la Mancha; Ley 3/2009, de 6 de abril, de Montes de Castilla y León y la Ley 7/2012, de 28 de junio, de montes de Galicia. Junto a estas disposiciones, se podrían destacar también todas las normas autonómicas sobre espacios naturales protegidos.

Por otro lado, los entes locales también ostentan decisivas competencias que afectan al ámbito forestal. En concreto, estas entidades tienen facultades de ordenación, explotación y mejora de sus bienes, previstas en el artículo 84 del Real Decreto Legislativo 781/1986, de 18 de abril, por el que se aprueba el texto Refundido de las Disposiciones vigentes en materia de Régimen Local y en los artículos 38 a 40 del Real Decreto 1372/1986, de 13 de junio, por el que se aprueba el Reglamento de Bienes de las Entidades Locales.

La Ley 43/2003 de Montes ha revitalizado el papel de las Administraciones locales en la política forestal, concediéndoles una mayor 
participación en la adopción de decisiones que inciden directamente sobre sus propios montes, reconociendo con ello su papel como principales propietarios forestales públicos en España y su contribución a la conservación de unos recursos naturales que benefician a toda la sociedad.

El artículo 9 de la Ley 43/2003 precisa así que las entidades locales, en el marco de la legislación básica del Estado y de la legislación de las Comunidades autónomas, ejercen las siguientes competencias en materia forestal:

La gestión de los montes de su titularidad no incluidos en el Catálogo de Montes de Utilidad Pública.

La gestión de los montes catalogados de su titularidad cuando así se disponga en la legislación forestal de la comunidad autónoma.

La disposición del rendimiento económico de los aprovechamientos forestales de todos los montes de su titularidad, sin perjuicio de lo dispuesto en el artículo 38 de la Ley de Montes en relación con el fondo de mejoras de montes catalogados o, en su caso, de lo dispuesto en la normativa autonómica.

La emisión de informe preceptivo en el procedimiento de elaboración de los instrumentos de gestión relativos a los montes de su titularidad incluidos en el Catálogo de Montes de Utilidad Pública.

La emisión de otros informes preceptivos previstos en esta ley, relativos a los montes de su titularidad.

Aquellas otras que, en la materia objeto de esta ley, les atribuya, de manera expresa, la legislación forestal de la comunidad autónoma u otras leyes que resulten de aplicación.

\section{LA PRINCIPAL NORMA REGULADORA DE LOS BOSQUES: LEY ESTATAL 43/2003, DE 21 DE NOVIEMBRE, DE MONTES}

Tras quedar en el camino en los últimos años diversos anteproyectos, proyectos y propuestas de reformas de la Ley de Montes de 1957, no fue sino hasta la aprobación de la Ley 43/2003, de 21 de noviembre, cuando por fin se derogó la legislación preconstitucional en la materia. Resultaba ineludible la obligación del Estado, en virtud de su competencia para dictar la legislación básica en materia de medio ambiente y de montes y aprovechamientos forestales, de aprobar una nueva Ley forestal que recompusiese de un modo unitario la materia y permitiese una tutela integral del bosque. La numerosa y asistemática normativa forestal vigente hasta el momento en nuestro país no respondía en modo alguno a estos perfiles.

La nueva norma, en línea con el Derecho forestal internacional y comunitario europeo, tiene en cuenta los múltiples usos que nuestra sociedad 
demanda hoy del monte pero, sobre todo, se basa en la priorización de la protección ambiental del bosque, en la tutela de la dimensión biológica del bosque. Así lo defiende nuestra Carta Magna y la jurisprudencia del máximo intérprete constitucional, y en esta dirección se han movido la Ley de Conservación de Espacios Naturales y la posterior legislación forestal autonómica. En nuestros días, una política forestal cualquiera, no encuadrada o apoyada por una política ambiental, está destinada a perder todo su significado 5 .

El moderno Derecho ambiental no exige una protección a ultranza de los bosques, que los convierta en piezas de museo, sino que aboga por una gestión sostenible de los montes, por su aprovechamiento a través de las técnicas selvícolas con el máximo respeto a las leyes de la naturaleza. Sólo fomentando esa gestión ordenada de nuestros bosques se puede garantizar su conservación y expansión, y, por tanto, el cumplimiento de sus decisivas funciones sociales y medioambientales.

También la Ley 42/2007, de 13 de diciembre, del Patrimonio Natural y de la Biodiversidad, que ha derogado a la Ley 4/1989, se centra en la prevalencia de la protección ambiental sobre la ordenación territorial y urbanística, y establece que las Administraciones competentes garantizarán que la gestión de los recursos naturales se produzca con los mayores beneficios para las generaciones actuales, sin merma de su potencialidad para satisfacer las necesidades y aspiraciones de las generaciones futuras, velando por el mantenimiento y conservación del patrimonio, la biodiversidad y los recursos naturales existentes en todo el territorio nacional, con independencia de su titularidad o régimen jurídico, atendiendo a su ordenado aprovechamiento y a la restauración de sus recursos renovables. Los principios que inspiran la Ley 42/2007 se basan, desde la perspectiva de la consideración del propio patrimonio natural, en el mantenimiento de los procesos ecológicos esenciales y de los sistemas vitales básicos, en la preservación de la diversidad biológica, genética, de poblaciones y de especies, y en la preservación de la variedad, singularidad y belleza de los ecosistemas naturales, de la diversidad geológica y del paisaje.

En este sentido, la propia exposición de motivos de la Ley 43/2003 advierte que la norma se inspira en unos principios que vienen enmarcados en el concepto primero y fundamental de la gestión forestal sostenible. A

5 Como señaló la declaración de la Asamblea de Naciones Unidas, en su sesión especial de junio de 1997, "la ordenación, la conservación y el desarrollo sostenible de todos los tipos de bosques son fundamentales para el desarrollo económico y social, la protección del medio ambiente y los sistemas sustentadores de la vida en el planeta. Los bosques son parte del desarrollo sostenible". 
partir de él se pueden deducir los demás: la multifuncionalidad, la integración de la planificación forestal en la ordenación del territorio, la cohesión territorial y subsidiariedad, el fomento de las producciones forestales y del desarrollo rural, la conservación de la biodiversidad forestal, la integración de la política forestal en los objetivos ambientales internacionales, la cooperación entre las Administraciones y la obligada participación de todos los agentes sociales y económicos interesados en la toma de decisiones sobre el medio forestal.

En la elaboración de la Ley 43/2003 jugó un papel decisivo la Estrategia Forestal Española, impulsada por el trabajo de la Dirección General de Conservación de la Naturaleza y aprobada el 17 de marzo de 1999 por la Conferencia Sectorial de Medio Ambiente, así como el Plan Forestal Español, aplicación en el tiempo y el espacio de la Estrategia Forestal, y que fue aprobado por Consejo de Ministros en julio de 2002.

\section{LAS ACTUACIONES DE LA UNIÓN EUROPEA EN MATERIA FORESTAL}

La Unión Europea no cuenta todavía con una política forestal general común, por lo que esta materia sigue siendo esencialmente competencia de los Estados miembros. De acuerdo con el principio de subsidiariedad y con el de complementariedad ${ }^{6}$, los Estados miembros son responsables de la planificación y la ejecución de los programas forestales nacionales o los instrumentos equivalentes, en el contexto de una gestión forestal sostenible.

No obstante, el sector forestal se ve afectado por determinadas políticas comunitarias como las de desarrollo rural, protección contra los incendios y contaminación atmosférica, conservación de la biodiversidad (Natura 2000), aplicación del Convenio sobre el cambio climático, investigación e, incluso, competitividad de la silvicultura. La gestión, la conservación y el desarrollo sostenible de los bosques son temas esenciales hoy dentro de otras políticas comunes vigentes como la de medio ambiente y la política agrícola común $(\mathrm{PAC})^{7}$.

6 Comunicación de la Comisión COM 1999, 218 y Resolución del Consejo 8080/99.

7 Alrededor del 90\% de los fondos de la Unión Europea destinados a los bosques provienen del Fondo Europeo Agrícola de Desarrollo Rural (Feader). Durante el periodo de programación 2007-2013, se destinaron unos 5.400 millones de euros del presupuesto del Feader a cofinanciar medidas específicas para los bosques. En el marco de los programas de desarrollo rural, se programó un gasto público de unos 8.200 millones de euros para el periodo $2015-2020$ (27\% para reforestación, $18 \%$ para mejorar la capacidad de adaptación y $18 \%$ para la prevención de daños). Puede verse 
Por otra parte, en el marco de la política de cohesión se cofinancian proyectos forestales con cargo al Fondo Europeo de Desarrollo Regional (en especial, prevención de incendios, producción de energías renovables y preparación al cambio climático). El Fondo de Solidaridad pretende, por su parte, ayudar a los Estados miembros a hacer frente a catástrofes naturales graves, como los temporales y los incendios ${ }^{8}$.

También existe el Mecanismo de Protección Civil de la Unión Europea ${ }^{9}$, que puede activarse en caso de crisis que superen la capacidad de respuesta de los Estados miembros, como algunos incendios forestales.

Cada vez se hace más necesaria pues una acción coordinada a nivel europeo en materia forestal. La mayoría de las disposiciones normativas de la Unión Europea aprobadas hasta ahora en materia forestal han estado ligadas a la PAC y han regulado principalmente acciones de fomento por medio del otorgamiento de subvenciones y ayudas. En el ámbito de la Unión Europea, el sector forestal se ha visto desde los años 80 con gran preocupación debido a su degradación, pero a la vez como un sector de futuro ya que el incremento de las masas forestales se ha considerado como una solución para ciertas tierras, detraídas en el pasado para su uso agrícola y con pocas perspectivas ante la situación excedentaria de muchos productos agrícolas. Ése ha sido el objetivo principal de la normativa comunitaria forestal, que siempre ha tenido un carácter secundario con respecto a la dominante política agrícola común.

En efecto, si bien sobre todo a partir del Acta Única Europea se han aprobado en la Unión Europea muchas disposiciones en materia forestal, no existe una política forestal autónoma, con sus propios objetivos y fundamentos jurídicos, que dé una respuesta global a los problemas y necesidades del sector, esto es, que tenga en cuenta la importancia medioambiental, económica y social del patrimonio forestal comunitario.

En su Resolución de 15 de diciembre de 1998 sobre una estrategia forestal para la Unión Europea, el Consejo invitó a la Comisión a que evaluara y continuara mejorando la efectividad del sistema europeo de supervisión del estado de los bosques y a que tuviera en cuenta todos los posibles efectos sobre los ecosistemas forestales. El sexto programa de acción comunitario en materia de medio ambiente 2001-2012 $2^{10}$ reconoce

http://www.europarl.europa.eu/factsheets/es/sheet/105/la-union-europea-y-los-bosques, consultada el 31 de enero de 2020.

8 Reglamento (CE) n. 2012/2002 del Consejo de la Unión Europea.

9 Decisión n. 1313/2013/UE.

10 Comunicación de la Comisión al Consejo, al Parlamento Europeo, al Comité Económico y Social y 
la necesidad de que la elaboración, aplicación y evaluación de las políticas ambientales estén respaldadas por un enfoque basado en el conocimiento, así como, en particular, la necesidad de un control de las múltiples funciones de los bosques de acuerdo con las recomendaciones de la Conferencia Ministerial sobre protección de los bosques en Europa, el Foro sobre los bosques de las Naciones Unidas y el Convenio sobre la biodiversidad.

Los incendios forestales y la contaminación atmosférica son los principales factores que ponen en peligro el desarrollo sostenible de los bosques de la Unión Europea y fueron objeto de desarrollo normativo mediante el Reglamento (CEE) n. 3528/86 del Consejo, de 17 de noviembre de 1986, relativo a la protección de los bosques en la Comunidad contra la contaminación atmosférica, y el Reglamento (CEE) n. 2158/92 del Consejo, de 23 de julio de 1992, relativo a la protección de los bosques comunitarios contra los incendios. Ambos Reglamentos expiraron el 31 de diciembre de 2002.

La Unión deseó dar continuidad a la vigilancia de los bosques integrando el Reglamento de protección de los bosques contra los incendios forestales, así como el Reglamento para la protección de los bosques contra la contaminación atmosférica en una nueva medida denominada Eje Bosques: se trata del Reglamento (CE) n. 2152/2003 del Parlamento Europeo y del Consejo, de 17 de noviembre de 2003, sobre el seguimiento de los bosques y de las interacciones medioambientales en la Comunidad (Forest Focus), y del Reglamento (CE) n. 1737/2006 de la Comisión, de 7 de noviembre de 2006, que estableció disposiciones de aplicación del Reglamento 2152/2003.

Pero Forest Focus se aplicó desde el 1 de enero de 2003 hasta el 31 de diciembre de 2006 (con un presupuesto anual de 61 millones de euros, de los que 9 millones estaban destinados a la prevención de incendios).

En la Comunicación de la Comisión Europea titulada "Una nueva estrategia de la UE en favor de los bosques y del sector forestal" 11 , se destaca la nueva estrategia de la Unión a la vez que se plantea un marco europeo de referencia para la elaboración de políticas sectoriales que repercutan en los bosques. Dicha estrategia persigue principalmente dos objetivos: (1) garantizar la gestión sostenible de los bosques europeos; y (2) reforzar la contribución de la Unión al fomento de la gestión forestal sostenible y a la lucha contra la deforestación a nivel planetario.

El Comité Forestal Permanente (CFP) es el organismo de coordinación

al Comité de las Regiones, de 24 de enero de 2001, COM 200131 final.

11 Documento COM(2013)0659. 
entre la Comisión y los Estados miembros en la ejecución del plan de acción. Creado en 1989, el CFP representa las administraciones forestales de los Estados miembros de la UE. Cuenta con 27 miembros (designados por los Gobiernos de los Estados miembros de la UE) y está presidido por la Comisión Europea. Su papel es triple: consulta y gestión de medidas forestales específicas, foro de consulta ad hoc que asiste con sus conocimientos técnicos en la elaboración de medidas en materia forestal dentro de las distintas políticas comunitarias, y punto de intercambio de información entre los Estados miembros y la Comisión.

\section{ESPACIOS NATURALES PROTEGIDOS}

Entre los bosques y los espacios forestales en sentido amplio, aquellos que han sido declarados como espacios naturales protegidos disfrutan de una protección jurídica mucho más intensa. La declaración de espacio protegido supone el otorgamiento a ciertos territorios concretos de un régimen jurídico privilegiado, en atención a sus especiales cualidades naturales.

A nivel estatal, la Ley 42/2007, de 13 de diciembre, del Patrimonio Natural y de la Biodiversidad, que ha derogado a la Ley 4/1989, de 27 de marzo, de Conservación de los Espacios Naturales y de la Flora y Fauna Silvestres, constituye la norma básica en la materia (disposición final segunda de la Ley 42/2007).

La Ley 4/1989 había refundido los regímenes de protección que creó la antigua Ley de 2 de mayo de 1975 en las cuatro categorías de Parques, Reservas Naturales, Monumentos Naturales y paisajes Protegidos. La declaración y gestión de estos espacios naturales protegidos correspondía en todo caso a las Comunidades autónomas en cuyo ámbito territorial se encuentren ubicados. La única reserva que la Ley establecía a favor del Estado era la gestión de los denominados Parques Nacionales, integrados en la Red de Parques Nacionales, en virtud de su condición de espacios representativos de alguno de los principales sistemas naturales españoles. Sin embargo, la Ley 41/1997, de 5 de noviembre, modificó la Ley 4/89 para adaptarla a la sentencia del Tribunal Constitucional 102/1995, de 26 de junio, que anuló varios de sus preceptos por atribuir exclusivamente al Estado la gestión de los Parques Nacionales. La norma modificó varios artículos de la Ley 4/89 para adaptar su contenido a la doctrina constitucional e incorporó, asimismo, nuevos preceptos para regular los órganos de gestión y administración de los Parques Nacionales. 
Posteriormente, la sentencia 194/2004 del Tribunal Constitucional, de 10 de noviembre de 2004 -RTC 2004/194-, vino a confirmar la competencia exclusiva de las Comunidades autónomas en la gestión de los Parques Nacionales.

En la actualidad, el segundo capítulo del Título II de la Ley 42/2007 establece el régimen especial para la protección de los espacios naturales, partiendo de la definición de la Ley 4/1989, de 27 de marzo, con la incorporación específica de las Áreas Marinas Protegidas y la creación de la red de áreas marinas protegidas, en línea con las directrices de la Unión Europea, así como la posibilidad de crear espacios naturales protegidos transfronterizos. La ley mantiene la figura, definición y regímenes de protección de los Parques y de las Reservas Naturales de la Ley 4/1989, adaptando la definición de los Paisajes Protegidos al Convenio del paisaje del Consejo de Europa. La declaración y gestión de los espacios naturales protegidos corresponderá, en todo caso, a las Comunidades autónomas en cuyo ámbito territorial se encuentren ubicados.

Para estos espacios la Ley 42/2007 mantiene la posibilidad de crear zonas periféricas de protección, la declaración de utilidad pública, a efectos expropiatorios de los bienes y derechos afectados, así como la facultad de la Administración competente para el ejercicio de los derechos de tanteo y retracto.

La Ley regula también la Red Ecológica Europea Natura 2000, compuesta por los Lugares de Importancia Comunitaria, las Zonas Especiales de Conservación y las Zonas de Especial Protección para las Aves. Estos espacios tienen la consideración de espacios protegidos, con la denominación específica de espacios protegidos Red Natura 2000, con el alcance y las limitaciones que las Comunidades autónomas establezcan en su legislación y en los correspondientes instrumentos de planificación. Corresponde a las Comunidades autónomas definir estos espacios y dar cuenta de los mismos al Ministerio de Medio Ambiente a efectos de su comunicación a la Comisión Europea, así como fijar las medidas de conservación necesarias, que implicarán apropiadas medidas reglamentarias, administrativas o contractuales, y asegurar su inclusión en planes o instrumentos adecuados, que respondan a las exigencias ecológicas de los tipos de hábitats naturales y de las especies presentes en tales áreas, vigilando el estado de conservación y remitiendo la información que corresponda al Ministerio de Medio Ambiente, que presentará el preceptivo informe cada seis años a la Comisión Europea. La definición de estos espacios se realizará en todo caso 
conforme a los criterios fijados en la Directiva 92/43/CEE del Consejo, de 21 de mayo de 1992, relativa a la conservación de los hábitats naturales y de la fauna y flora silvestres.

Para asegurar la preservación de los valores que han dado lugar a la definición de estas zonas, se establecen por la Ley 42/2007 las correspondientes cautelas, de forma que cualquier plan, programa o proyecto que, sin tener relación directa con la gestión de un espacio de la Red Natura 2000, o sin ser necesario para la misma, pueda afectar de forma apreciable a los citados lugares, ya sea individualmente o en combinación con otros planes, programas o proyectos, se someterá a una adecuada evaluación de sus repercusiones en el lugar, de forma que las Comunidades autónomas correspondientes sólo manifestarán su conformidad con dicho plan, programa o proyecto tras haberse asegurado de que no causará perjuicio a la integridad del lugar en cuestión y, si procede, tras haberlo sometido a información pública. En este sentido, la Ley acepta que podrá realizarse el plan, programa o proyecto, pese a causar perjuicio, si existen razones imperiosas de interés público de primer orden que, para cada supuesto concreto, hayan sido declaradas mediante una ley o mediante acuerdo, motivado y público, del Consejo de Ministros o del órgano de Gobierno de la Comunidad autónoma. Por último, se establece que sólo se podrá proponer la descatalogación total o parcial de un espacio incluido en Red Natura 2000 cuando así lo justifiquen los cambios provocados en el mismo por la evolución natural, y previo trámite de información pública.

Pero las áreas protegidas se encuentran además afectadas por instrumentos internacionales de conformidad con, y en cumplimiento de lo dispuesto en los Convenios y acuerdos internacionales correspondientes (humedales de Importancia Internacional, sitios naturales de la Lista del Patrimonio Mundial, áreas marinas protegidas del Atlántico del nordeste, Zonas Especialmente Protegidas de Importancia para el Mediterráneo (ZEPIM), Geoparques, Reservas biogenéticas del Consejo de Europa, etc.) para las que el Ministerio de Medio Ambiente, con la participación de las Comunidades autónomas, elaborará, en el marco del Plan Estratégico Estatal del Patrimonio Natural y la Biodiversidad, unas directrices de conservación, que deberán ser aprobadas por acuerdo de la Conferencia Sectorial de Medio Ambiente, en paralelo con las correspondientes a las de la Red Natura 2000, como marco orientativo para la planificación y gestión de estos espacios. 


\section{EL CONCEPTO DE MONTE COMO ECOSISTEMA FORESTAL EN LA LEY 43/2003}

Frente al limitado concepto de monte que proporcionaba el artículo primero de la Ley de Montes del Estado de 8 de junio de 1957, que entendía por tal un terreno rústico no agrícola, estuviese o no poblado por especies forestales (ESTEVE PARDO, 1995), la Ley 43/2003 vino a consagrar en la legislación estatal básica el concepto amplio de monte que había recogido ya la legislación forestal autonómica, como terreno que principalmente cumple o puede cumplir funciones ambientales y protectoras.

En efecto, el concepto de monte del artículo 5 de la Ley estatal 43/2003 incorpora las diversas funciones del territorio forestal y da entrada a las Comunidades autónomas en el margen de regulación sobre terrenos agrícolas abandonados, suelos urbanos y urbanizables y la determinación de la dimensión de la unidad mínima que será considerada monte a efectos de la ley.

La Ley estatal de Montes define así de forma muy amplia al monte en su artículo 5 al entender por tal:

[...] todo terreno en el que vegetan especies forestales arbóreas, arbustivas, de matorral o herbáceas, sea espontáneamente o procedan de siembra o plantación, que cumplan o puedan cumplir funciones ambientales, protectoras, productoras, culturales, paisajísticas o recreativas. Tienen también la consideración de monte:

Los terrenos yermos, roquedos y arenales.

Las construcciones e infraestructuras destinadas al servicio del monte en el que se ubican.

Los terrenos agrícolas abandonados que cumplan las condiciones y plazos que determine la comunidad autónoma, y siempre que hayan adquirido signos inequívocos de su estado forestal.

Todo terreno que, sin reunir las características descritas anteriormente, se adscriba a la finalidad de ser repoblado o transformado al uso forestal, de conformidad con la normativa aplicable.

La definición se concreta en el apartado 2 del mismo precepto con una delimitación negativa:

No tienen la consideración de monte:

Los terrenos dedicados al cultivo agrícola.

Los terrenos urbanos y aquellos otros que excluya la comunidad autónoma en su normativa forestal y urbanística.

La Ley 3/2008 sienta pues una concepción positiva a la hora de catalogar los montes o terrenos forestales, en cuanto se basa en las características intrínsecas de las distintas áreas territoriales, eludiendo así la concepción 
residual que resultaría de la mera exclusión de las superficies destinadas a otros usos; a la vez al concepto de monte se han añadido también aquellos terrenos que cumplan o puedan cumplir funciones ambientales, protectoras, productoras, culturales, de paisaje o recreativas, con lo que no sólo se mejora el concepto sino que se hace más acorde con lo dispuesto en el artículo 45 de la Constitución, al tener en cuenta además de los aspectos de productividad, los medioambientales. Se establece, por último, una idea fundamental para la gestión forestal, consistente en que los montes, como ecosistemas que son, deben ser tratados de un modo integrado.

Con anterioridad a la aprobación de la ley estatal 43/2003, diversas leyes autonómicas habían dotado al concepto de monte de un sentido más abierto y positivo, reconociéndole además, de forma expresa, las múltiples funciones de carácter social que desempeña. Estas normas, por tanto, acentuaron los aspectos funcionales y finalistas, que quedaron integrados en el concepto.

Esta línea resulta claramente apreciable en Leyes autonómicas como las siguientes: 13/1990, de 31 de diciembre, de Protección y Desarrollo del Patrimonio Forestal de Navarra; 3/1993, de 9 de diciembre, Forestal de Valencia; 8/1998, de 26 de junio, de Conservación de la naturaleza y de espacios naturales de Extremadura; 5/1994, de 16 de mayo, de Fomento de los Montes Arbolados de Castilla y León; 16/1995, de 4 de mayo, Forestal y de protección de la naturaleza de la Comunidad de Madrid y 2/1992, de 15 de junio, Forestal de Andalucía. También se ofrece una definición integral de monte por las Leyes 3/2004, de 23 de noviembre, de Montes y Ordenación Forestal del Principado de Asturias; 15/2006, de 28 de diciembre, de Montes de Aragón y 3/2008, de 12 de junio, de Montes y Gestión Sostenible de Castilla-la Mancha.

\section{CLASIFICACIÓN Y RÉGIMEN JURÍDICO DE LOS MONTES: MONTES PÚBLICOS Y PRIVADOS}

Si hay un dato característico de los montes españoles desde el punto de vista de la propiedad es la enorme fragmentación que presenta. Hay cerca de 30 millones de parcelas forestales, dentro de las cuales las de propiedad pública tienen alrededor de cinco hectáreas de superficie media por parcela mientras que las de propiedad de los particulares cuentan de media con tres cuartos de hectárea. En conjunto, la superficie media de la parcela en España sobrepasa ligeramente una hectárea, lo que hace muy difícil la gestión de las mismas como unidades forestales. 
Por lo que se refiere a la titularidad de la propiedad, aproximadamente un tercio de la superficie forestal española es de titularidad pública, de la que una pequeña parte es de titularidad estatal. En efecto, sólo el 5\% de nuestros bosques públicos pertenecen al Estado; alrededor de un 30\% pertenecen a las CCAA y un $65 \%$ a las Entidades Locales. La mayoría de nuestros bosques, alrededor de un $65 \%$, son propiedad de los particulares. En la Unión Europea las estadísticas son similares, 2/3 partes de los bosques pertenecen a particulares.

Pues bien, la principal clasificación de los montes en nuestro derecho es la que distingue en función de su titularidad entre montes públicos y montes privados.

Son montes públicos los pertenecientes al Estado, a las Comunidades autónomas, a las entidades locales y a otras entidades de derecho público; mientras que son montes privados los pertenecientes a personas físicas o jurídicas de derecho privado, ya sea individualmente o en régimen de copropiedad.

Ahora bien, como precisa el importante artículo 4 de la Ley 43/2003, los montes, independientemente de su titularidad, desempeñan una función social relevante, tanto como fuente de recursos naturales como por ser proveedores de múltiples servicios ambientales, entre ellos, de protección del suelo y del ciclo hidrológico; de fijación del carbono atmosférico; de depósito de la diversidad biológica y como elementos fundamentales del paisaje. El reconocimiento de estos recursos y externalidades, de los que toda la sociedad se beneficia, obliga a las Administraciones públicas a velar en todos los casos por su conservación, protección, restauración, mejora y ordenado aprovechamiento.

En este sentido, hay que recordar que el artículo 33 de la Constitución establece el derecho a la propiedad privada como un derecho que no debe entenderse ilimitado. La función social del propio derecho lo delimita, en la medida que el articulo 128 reconoce que toda la riqueza del país, en sus distintas formas, y sea cual sea su titularidad, está subordinada al interés general.

Como ha señalado De Vicente Domingo (1995), el régimen jurídico del monte ya no es explicable solamente desde el referente titularidad-función característico de la legislación forestal preconstitucional; hoy la diversidad funcional pesa más que la titularidad y se busca un resultado equilibrado en la protección, con independencia del sujeto, público o privado, al que pertenezca el monte. 
Pues bien, en la definición y regulación de los montes públicos y privados la Ley de Montes de 2003 introdujo una destacable claridad. Así, la norma optó por la declaración de los montes catalogados de utilidad pública como de dominio público, constituyéndose el dominio público forestal con estos montes junto con los montes comunales y los restantes montes afectados a un uso o un servicio público.

Para todos estos montes contempla la Ley un mismo régimen jurídico, estableciendo sobre todo el régimen de usos (aprovechamientos, autorizaciones o concesiones) en el artículo 15 (precepto que fue modificado por la Ley 25/2009, de 22 de diciembre, de modificación de diversas leyes para su adaptación a la Ley sobre el libre acceso a las actividades de servicios y su ejercicio, que le añadió un apartado 5 al citado artículo 15 para prever que "en los procedimientos de concesión y autorización de actividades de servicios que vayan a realizarse en montes demaniales, sin perjuicio de lo dispuesto en la regulación de los montes comunales, se respetarán los principios de publicidad, objetividad, imparcialidad y transparencia"). Así, la Administración gestora de los montes demaniales podrá dar carácter público a aquellos usos respetuosos con el medio natural, siempre que se realicen sin ánimo de lucro y de acuerdo con la normativa vigente, en particular con lo previsto en los instrumentos de planificación y gestión aplicables, y cuando sean compatibles con los aprovechamientos, autorizaciones o concesiones legalmente establecidos. Asimismo, se someterá a otorgamiento de autorizaciones aquellas actividades que, de acuerdo con la normativa autonómica, la requieran por su intensidad, peligrosidad o rentabilidad. En los montes catalogados será preceptivo el informe favorable del órgano forestal de la comunidad autónoma. La Administración competente someterá a otorgamiento de concesión todas aquellas actividades que impliquen una utilización privativa del dominio público forestal. En los montes catalogados, esta concesión requerirá el informe favorable de compatibilidad con la persistencia de los valores naturales del monte por parte del órgano forestal de la comunidad autónoma.

La Ley mantiene la importancia de la institución del Catálogo de Montes de Utilidad Pública ${ }^{12}$, de gran tradición histórica en la regulación jurídica de los montes públicos en España - el Catálogo nació como una relación de propiedades que la Administración podía conservar, esto es, de

12 Tanto la Ley 43/2003 como su reforma operada por la Ley 10/2006 mantuvieron la vigencia de la Orden Ministerial de 31 de mayo de 1966 (RCL/1966/1085) por la que se dictaron las normas precisas para actualizar las relaciones de Montes de Utilidad Pública, subsanando las deficiencias que pudieran haberse observado e introduciendo todas las modificaciones o incidencias producidas desde el año 1901 a fin de perfeccionar su identificación física y, en su caso, las inscripciones registrales. 
bienes exceptuados de la desamortización (GUAITA, 1986). En este sentido, se ampliaron en la Ley 43/2003 los motivos de catalogación al añadirse aquellos que más contribuyen a la conservación de la diversidad biológica $\mathrm{y}$, en particular, aquellos que constituyan o formen parte de espacios naturales protegidos o espacios de la red europea Natura 2000.

La inclusión y exclusión de montes en el Catálogo de Montes de Utilidad Pública y la llevanza de éste corresponde a las Comunidades autónomas en sus respectivos territorios. Las Comunidades autónomas darán traslado al Ministerio de Medio Ambiente de las inscripciones que practiquen así como de las resoluciones administrativas y sentencias judiciales firmes que conlleven modificaciones en el catálogo, incluidas las que atañen a permutas, prevalencias y resoluciones que, con carácter general, supongan la revisión y actualización de los montes catalogados.

La inclusión en el Catálogo de Montes se hará de oficio o a instancias del titular, y se adoptará por acuerdo del órgano competente que determine cada Comunidad autónoma, a propuesta de su respectivo órgano forestal, previa instrucción del correspondiente procedimiento en el que deberá ser oída la Administración titular y, en su caso, los titulares de derechos sobre dichos montes. Por su parte, la exclusión de un monte del Catálogo de Montes de Utilidad Pública sólo procederá cuando haya perdido las características por las que fue catalogado. La exclusión parcial o permuta de una parte no significativa de un monte catalogado podrá ser autorizada por la comunidad autónoma, a propuesta de su órgano forestal, siempre que suponga una mejor definición de la superficie del monte o una mejora para su gestión y conservación.

La desafectación de los montes catalogados del dominio público forestal requerirá su previa exclusión del catálogo.

En relación con los montes patrimoniales, dispone el artículo 19 de la Ley que la usucapión o prescripción adquisitiva sólo se dará mediante la posesión en concepto de dueño, pública, pacífica y no interrumpida durante 30 años. Se entenderá interrumpida la posesión a efectos de la prescripción por la realización de aprovechamientos forestales, por la iniciación de expedientes sancionadores o por cualquier acto posesorio realizado por la Administración propietaria del monte.

Por lo que se refiere a los montes privados, se gestionan por su titular. Ahora bien, los titulares de estos montes podrán contratar su gestión con personas físicas o jurídicas de derecho público o privado o con los órganos forestales de las Comunidades autónomas donde el monte radique. 
La gestión de estos montes se ajustará, en su caso, al correspondiente instrumento de gestión o planificación forestal.

Pero la Ley 43/2003, al igual que hizo con los montes catalogados, también reforzó la figura de los montes protectores y su registro, cuya declaración se estimuló con incentivos económicos.

Las Comunidades autónomas podrán calificar como protectores, a instancia del propietario, aquellos montes privados que cumplan alguna de las condiciones que para los montes públicos establece el artículo 13 de la Ley 43/2003. Las Comunidades autónomas también podrán crear registros de montes protectores como registros de carácter administrativo.

La clasificación y desclasificación de un monte protector, o parte de éste, y su consiguiente inclusión o su exclusión en el registro de montes protectores se hará por el órgano forestal de la comunidad autónoma correspondiente, previo informe del propietario.

\section{LOS PLANES DE ORDENACIÓN DE LOS RECURSOS FORESTALES}

Junto a la Estrategia y el Plan forestal, entre los instrumentos de planificación forestal que recoge la LMo destacan, sin duda alguna, los planes de ordenación de los recursos forestales (PORF).

Estos planes se configuran como instrumentos de planificación forestal integrados en el marco de la ordenación del territorio, con lo que la planificación y gestión forestales se conectan con el decisivo ámbito de la ordenación territorial.

Corresponde a las Comunidades autónomas la elaboración de estos planes de ordenación, cuyo contenido será obligatorio y ejecutivo en las materias reguladas en la ley. Asimismo, tendrán carácter indicativo respecto de cualesquiera otras actuaciones, planes o programas sectoriales. Ahora bien, la Ley obliga a consultar a las entidades locales y, a través de sus órganos de representación, a los propietarios forestales privados, a otros usuarios legítimos afectados y a los demás agentes sociales e institucionales interesados.

El apartado 6 del artículo 31 de la LMo recoge los elementos que podrán incluir los PORF.

El ámbito territorial de los PORF serán los territorios forestales con características geográficas, socioeconómicas, ecológicas, culturales o paisajísticas homogéneas, de extensión comarcal o equivalente. 
La nueva política forestal instaurada por la LMo de 2003 parte de la consideración de que el aprovechamiento correcto de los recursos naturales del monte (obtención de madera y resinas, piñones y frutos secos, corcho, plantas aromáticas y medicinales, etcétera) no es incompatible con su conservación, sino complementario de ella. De ahí la importancia de que las Comunidades autónomas, en el ejercicio de sus competencias, practiquen una ordenación y gestión forestales basadas en Planes para asegurar la sostenibilidad, tanto en los montes de Utilidad Pública, como en los de titularidad privada.

En la actualidad, el mercado español de la madera es deficitario porque los aprovechamientos que se realizan anualmente no llegan a cubrir las necesidades existentes. Nuestros montes maderables se aprovechan por debajo de sus posibilidades, al aplicarse normas conservadoras con la finalidad de mantener el capital monte en unos niveles de seguridad. Por ello, como destaca la Estrategia Forestal Española, se hace necesario fomentar el crecimiento sostenible del sector maderero, apostando por un aumento de la producción de calidad.

\section{CONCLUSIONES}

En la línea evolutiva de la legislación española sobre protección de los bosques, cuyo primer eslabón de importancia en el Derecho español fue la Ley de Montes de 1863, ha predominado casi absolutamente la preocupación por la función económica del monte, por su explotación racional y sólo desde muy recientemente se valora su importancia medioambiental. En este sentido, hay que recordar que, no sólo en España sino a nivel mundial, hasta hace muy poco el bosque se consideraba como un bien prácticamente ilimitado. Como señalaba Clawson (1975, p. 78), la opinión generalizada era que el bosque no tenía fin y además, era necesario preparar la tierra para la agricultura.

La Ley de Montes de 8 de junio de 1957 se podía definir como una ley de propiedad forestal más que del medio ambiente forestal. La norma se aprobó en un momento histórico en el que la conciencia ambiental no estaba muy arraigada en la sociedad. La filosofía subyacente en la Ley es de corte productivista (GROOME, 1989).

Con la aprobación de la Constitución Española de 1978 se empieza a considerar al bosque en su conjunto como objeto de protección ambiental (ESTEVE PARDO, 1995) y se va a producir un importante cambio de 
enfoque desde el que contemplar toda la normativa forestal.

Además hay que tener en cuenta que se produce una descentralización del poder, asumiendo competencias de desarrollo legislativo y ejecutivo las Comunidades autónomas.

La Constitución española contiene un importante reconocimiento del derecho al medio ambiente y un decisivo mandato para los poderes públicos, al obligarles a velar por la utilización racional de todos los recursos naturales.

La Ley de Montes del Estado español de 2003 ofrece una regulación medioambiental de los bosques y utiliza un concepto amplio de bosque como terreno que principalmente cumple funciones ambientales y protectoras. La Ley incorpora las diversas funciones del territorio forestal.

Por lo que se refiere al Derecho de la Unión Europea, la mayoría de las disposiciones normativas aprobadas hasta ahora en materia forestal han estado ligadas a la Política Agraria y han regulado principalmente acciones de fomento por medio del otorgamiento de subvenciones y ayudas. En el ámbito de la Unión Europea, el sector forestal se ha visto desde los años 80 del siglo XX con gran preocupación debido a su degradación, pero a la vez como un sector de futuro ya que el incremento de las masas forestales se ha considerado como una solución para ciertas tierras, detraídas en el pasado para su uso agrícola y con pocas perspectivas ante la situación excedentaria de muchos productos agrícolas. Ése ha sido el objetivo principal de la normativa forestal europea, que siempre ha tenido un carácter secundario con respecto a la dominante política agrícola común.

En efecto, si bien sobre todo a partir del Acta Única Europea de 1986 se aprobaron en la Unión Europea muchas disposiciones en materia forestal, no existe una política forestal autónoma, con sus propios objetivos y fundamentos jurídicos, que dé una respuesta global a los problemas y necesidades del sector, esto es, que tenga en cuenta la importancia medioambiental, económica y social del patrimonio forestal comunitario.

\section{REFERENCIAS}

CALVO SÁNCHEZ, L. (Coord.). Comentarios sistemáticos a la Ley 43/2003, de 21 de noviembre, de Montes. Estudios de Derecho estatal y autonómico (coordinador). Madrid: Thomson-Civitas, 2005.

CLAWSON, M. Forest for whom and for what? Baltimore: John Hopkins University Press, 1975. 
DE VICENTE DOMINGO, R. Espacios forestales (su ordenación jurídica como recurso natural). Madrid: Civitas, 1995.

ESTEVE PARDO, J. Realidad y perspectivas de la ordenación jurídica de los montes (Función ecológica y explotación racional). Madrid: Civitas, 1995.

GARCÍA DE ENTERRÍA, E. Las formas comunitarias de la propiedad forestal. Madrid: Santander, 1986

COTTON, C. Buying destruction: a Greenpeace report for corporate consumers of forest products. Amsterdam: Greenpeace International, 1991.

GROOME, H. Historia de la política forestal. In: HERNÁNDEZ-AGERO, C. O. El libro rojo de los bosques españoles, Madrid: ADENA-WWF España, 1989.

GUAITA, A. Régimen jurídico-administrativo de los montes. Santiago de Compostela: Porto y Cía., 1956.

GUAITA, A. Derecho Administrativo: aguas, montes y minas. Madrid: Civitas, 1986.

LÁZARO BENITO, F. La ordenación constitucional de los recursos forestales. Madrid: Tecnos, 1993.

MARRACO SOLANA, S. La política forestal española: evolución reciente y perspectivas. Revista de Estudios Agro-Sociales, n. 158, p. 11-28, 1991.

MARTÍN MATEO, R. Tratado de Derecho Ambiental. Madrid: Trivium, 1992.

MORENO MOLINA, J. A. La protección ambiental de los bosques. Madrid: Marcial Pons, 1998.

MORENO MOLINA, J. A. Defensa frente a los incendios forestales. In: CALVO SÁNCHEZ, L. (Coord.). Comentarios sistemáticos a la Ley 43/2003, de 21 de noviembre, de Montes. Estudios de Derecho estatal y autonómico. Madrid: Thomson-Civitas, 2005.

NIETO, A. Bienes comunales de los Montes de Toledo. Madrid: Ayuntamiento de Los Yébenes; Civitas, 1991.

OLIVÁN DEL CACHO, J. La protección del medio ambiente en la legislación forestal. Revista Aragonesa de Administración Pública, n. 2, p. 135-178, 1993. 
OLIVÁN DEL CACHO, J. Aspectos jurídico-administrativos de los incendios forestales: especial referencia a la Comunidad Autónoma de Cataluña. Autonomies - Revista Catalana de Derecho Público, n. 20, p. 235-258, 1995. PARADA VAZQUEZ, J. R. Derecho Administrativo: bienes públicos y urbanismo. Madrid: Marcial Pons, 1989.

ORTEGA ÁlVAREZ, L. El concepto de Derecho del medio ambiente. In: ORTEGA ÁlVAREZ, L. (Dir.). Lecciones de Derecho del medio ambiente. 4. ed. Valladolid: Lex Nova, 2005. p. 55-64.

SARASÍBAR IRIARTE, M. El derecho forestal ante el cambio climático: las funciones ambientales de los bosques. Pamplona: Aranzadi, 2007.

Artículo recibido en: 11/02/2020.

Artículo aceptado en: 13/04/2020.

\section{Cómo citar este artículo (ABNT):}

MORENO MOLINA, J. A. Regulación de los bosques en el Derecho Español y de La Unión Europea. Veredas do Direito, Belo Horizonte, v. 17, n. 37, p. 35-60, ene.-abr. 2020. Disponible en: http://revista.domhelder.edu. br/index.php/veredas/article/view/1772. Acceso el: día de mes de año. 